\section{La exterioridad del mal en Paul Ricoeur}

\author{
Sergio Moya Mena*
}

\section{Resumen}

El artículo aborda la importancia del problema del origen del mal en la obra de Paul Ricoeur y especialmente en el Mito Adámico, que el filósofo francés estudia en La simbólica del mal. A través de un estudio de los símbolos, Ricoeur demuestra cómo el hombre ha concebido el mal desde la visión trágica a la visión ética, una ruta que irá de la exterioridad a la interioridad. Sin embargo, es muy relevante en el mito de la creación bíblica la importancia de la exterioridad del mal representado por la Serpiente. Ciertamente el hombre, merced a su falibilidad, posibilita la entrada del mal en el mundo, pero resulta necesario también tomar en cuenta el papel de figuras contrapuestas a la figura central del Hombre y que introducen el nivel de la exterioridad en el origen del mal. El hombre no es originador del mal, sino cooriginador.

* Licenciado en Relaciones Internacionales con énfasis en Política Internacional (Universidad Nacional). Profesor de la Escuela de Ciencias Políticas (UCR). Autor de Crisis y renovación del socialismo democrático (1999); Cambio social y politicas progresistas en la globalización (2004). sergio@wiphala.org

Rec. 14-12-05 Acep. 28-03-06

\section{Palabras clave}

El problema del mal, Mito adámico, Símbolo, Falibilidad, Exterioridad del mal

\section{Abstract}

This article analyzes the importance of the problem regarding the origin of evil in Paul Ricoeur's work, particularly in the Adamic Myth that the French philosopher studies in the "Symbolism of Evil". Through a study of symbols, Ricoeur demonstrates that man has conceived evil from the tragic vision to the ethical vision, a route that goes from the externality to the interiority. Nevertheless, the importance of the externality of evil, represented by the Serpent, is very relevant in the Biblical creation myth. Certainly, man, thanks to his fallibility, makes possible the entrance of evil in the world, but it is necessary also to take into account the role of figures opposing the central figure of Man, which introduce the level of externality in the origin of evil. Man is not originator of evil, but Co-originator.

\section{Key words:}

The problem of evil. Adamic Myth. Symbol. Fallibility. Externality of Evil

\section{Introducción}

El tema del mal es sin duda uno de los problemas más añejos de la filosofía ¿Cuál es su origen? ¿Cuál es su naturaleza ¿Cuál es la dimensión real de su vinculación con el ser humano?

En el cristianismo como en otras religiones monoteístas, se supone 
que Dios es omnipotente, omnisciente y perfectamente bueno, y aun así hay mal en el mundo. Uno de los argumentos del ateísmo más recurrentes establece que si un ser omnipotente podría prevenir el mal -si quisiera- un ser omnisciente sabría cómo hacerlo, y un ser perfectamente bueno siempre decidiría hacerlo; estas serían pruebas de que Dios no existe. Este es apenas un ejemplo de las intensas discusiones que el mal ha suscitado entre filósofos y teólogos, desde hace cientos de años.

De todos los problemas de la existencia humana quizás ningún otro resulta tan actual para la ciencia como el mal. En el ámbito de la psiquiatría, el lidiar con individuos perversos como los serial killers hace pensar a muchos científicos forenses que determinadas personas no son simplemente perturbados, sino malvados, pues su crueldad habitual desafía toda explicación psicológica o intento de tratamiento. No obstante, estos científicos evitan utilizar la palabra "mal", pues alegan que su uso causaría un peligroso desliz del ámbito clínico al juicio moral. "El mal es endémico, es constante, es potencial en todos nosotros. Casi todo el mundo ha cometido actos malvados", dice Robert I.
Simon, profesor de psiquiatría de la Universidad de Georgetown, (Simon, 2005.) quien agrega:

The capacity for evil is a human universal (...) There is a continuum of evil, of course, ranging from trivial evils like cutting someone off in traffic, to greater evils like those perpetrated by serial killers. But within us all are the roots of evil. (Begley, 2001).

Para la psiquiatría estaríamos entonces ante un elemento intrínseco en la psique del individuo. Determinar el origen del mal no es aquí un problema, sino más bien clasificarlo o medirlo. Sin negar la relevancia que pueda tener la cuantificación o medición del mal, está claro que desde la filosofía o la teología, se trataría apenas de una de las tantas aristas que ofrece este complejo fenómeno y obviamente el interés en el problema no se quedaría ahí. Si los humanos somos básicamente malos, ¿por qué rechazamos a gente como Hitler, Stalin o Pol Pot y por otro lado acogemos cálidamente a personajes como el Dalai

Lama, Gandhi o la Madre Teresa de Calcuta? Deseamos la paz la justicia, la igualdad, la fraternidad. Básicamente somos personas buenas. Si somos básicamente buenos ¿por qué entonces hacemos el mal? ¡Cuán oportuno resulta frente a 
este cuestionamiento de Rom. 7:19, "De hecho no hago el bien que quiero, sino el mal que no quiero!

Frente a esto, algunos piensan que el mal es algo real no sólo psicológica o históricamente, sino de un modo más amplio, de manera que los males particulares son definidos como especies de un mal real general. Varios autores han afirmado que el problema del mal es exclusivamente de índole moral; otros que es de naturaleza metafísica. En ambos casos puede insistirse que el mal es predominantemente una realidad o primariamente un valor (o más bien un disvalor). A veces, se concluye que la definición de mal como realidad y como disvalor no son incompatibles, puesto que realidad y valor, por un lado y negación de realidad y disvalor, por el otro, son equiparables.

El mal ha sido siempre uno de los más desconcertantes problemas humanos. Por eso Paul Ricoeur afirma que el mal "es tan antiguo como el más antiguo de los seres", de manera que los estudios filosóficos sobre el mal son abundantes. Consciente de esas contribuciones previas, este trabajo pretende constituirse en una aproximación al problema del mal en Paul Ricoeur, quien nos invita a una nueva forma de pensarlo. Ricoeur no se propone expresamente plantear una metafísica del mal (por lo menos en Finitud y Culpabilidad), como San Agustín o Santo Tomás, quienes se preguntan por la naturaleza del mal, sino que analiza e interpreta el lenguaje del mal por medio de una hermenéutica de los símbolos, los mitos y el lenguaje. Concretamente, esta investigación plantea situar la obra de Ricoeur y sus referencias a la exterioridad del mal en el marco del pensamiento filosófico y teológico, problematizar el análisis de la exterioridad del mal en Finitud $y$ culpabilidad, y otras obras, analizar el problema del origen real del mal y sus agentes en el mito adámico y la tradición judeo-cristiana y determinar los alcances y dimensiones de la exterioridad del mal en Paul Ricoeur.

\section{El tema del mal en el marco del pensamiento occidental}

Resulta conveniente intentar una definición del mal que nos permita saber a qué atenernos en esta corta travesía que iniciaremos, primero de forma introductoria, haciendo referencia a la idea del mal en el pensamiento moderno (fundamentalmente en Kant) y después de la mano de Paul Ricoeur. 
El jesuita Joseph F. Kelly observa muy acertadamente que si bien podemos identificar fácilmente un acto malo sin necesidad de la filosofía o la teología, definir "mal" resulta algo más complejo. Para Jeffrey Burton Rusell, la esencia del mal es "el abuso sobre un ser sintiente que puede sentir dolor". Es el dolor lo que importa. El mal es percibido por la mente e inmediatamente sentido por las emociones; es percibido como dolor deliberadamente inflingido. (Kelly, 200:3) deliberadamente significa que la persona que comete el mal sabe lo que esta haciendo. Por ser sintiente también podría entenderse a Dios, a quien los creyentes ofenden o decepcionan violando los mandamientos divinos o al rechazar su amor. Esta definición tiene que ver fundamentalmente con el mal moral y la interacción del ser humano con otros seres sintientes.

Otra forma de mal es el mal natural que se refiere al mal hecho contra nosotros por la naturaleza, aunque cabría preguntar si el mal natural es realmente "mal". Un tercer tipo de mal es el mal ontológico, que en el pasado tuvo una fortuna inconstante y casi no tiene relevancia ahora. Algunos pensadores occidentales creyeron que ciertos tipos de seres eran inherentemente superiores a otros, como un ser humano racional en comparación con un animal. Ontológicamente un ser humano como ser racional es superior a un perro, pero ¿cuál ser es moralmente superior: un humano que comete crímenes o un perro fiel que ayuda a un ciego?

Este breve repaso sobre los distintos tipos de mal conduce a una importante conclusión respecto a la concepción del mal: los pensadores occidentales distinguen entre el mal, el hecho inescapable de que seres inteligentes deliberadamente imponen sufrimiento hacia otros seres sintientes y males, las múltiples formas en las que el mal puede manifestarse.

Mucha de la dificultad acerca del mal deriva del monoteísmo, creencia en un solo dios, usualmente una poderosa y buena deidad que teóricamente puede detener el mal pero que prácticamente no lo hace. En efecto, dentro del monoteísmo el tema del origen del mal ha planteado explicaciones disímiles. Para unos, el mal proviene en definitiva de Dios o de la causa primera; si Dios es la causa de todo, y consecuentemente también del mal, éste sería inherente al creador. De acuerdo con Vittorio Possenti, el problema del mal hay que situarlo ante Dios, pues sin él no se explica el sufrimiento, no son derrotados ni el dolor ni el mal, (Castillo Ávila, 
2004). Una concepción alternativa plantearía que Dios alberga en sí la oscuridad y una huella del mal. En Él cohabitaría luz y oscuridad, una mano derecha y una izquierda: el mal formaría parte, acaso vencida pero parte al fin de cuentas, de esa mano izquierda. Otra respuesta plantearía que "Dios permite el mal (moral), que en todo caso encuentra su único origen en el acto de la libertad finita".

\section{Tesis sobre los orígenes del mal}

Para explicar el origen del mal se han planteado varias propuestas. Algunas de éstas serían:

- $\quad$ El mal procede en definitiva de Dios o de la Causa primera: Si Dios es la causa de todo, también lo sería del mal, éste inhiere a Dios. Aunque de la expresión "el mal procede de Dios", no debe entenderse en el sentido de que el mal inhiera en Dios, sino solo que la razón de que haya mal es la producción de un mundo. Finalmente el mal puede concebirse como una prueba enviada por Dios al hombre para acreditar su paciencia y ponerlo en la vía de la santidad, es el clásico dilema de Job.
- $\quad$ El mal tiene su origen en el hombre o en algunas de sus actividades: Se puede entender de varios modos. Podrían suponerse que la sola rebelión del hombre contra Dios o su alejamiento de él son la causa del mal. En segundo término puede alegarse que el mal reside en la naturaleza humana, en el tanto que solamente ésta no es indiferente al mal.

- El mal es consecuencia del azar, de la naturaleza, de la materia $o$ de otras fuentes. (Ferrater, 2001:228). Estas teorías buscan un elemento que explique el mal, sin tratar en la mayor parte de los casos de justificarlo. En otras de ellas se determinan modos de producirse el mal sin tratar en la mayor parte de justificarlo. En otras de ellas se determinan modos de producirse el mal y se habla de causa material, formal, eficiente $\mathrm{y}$ final del mal, etc. En muchos casos, la teoría acerca del origen del mal está ligada a la doctrina sustentada sobre su naturaleza. 


\section{El problema del mal a partir de la modernidad: Kant}

Para muchos filósofos y teólogos, en consonancia con las tesis de la psiquiatría, el mal sería algo que está en el hombre y en sus acciones. La rebelión del hombre contra Dios es apenas un ejemplo de esto. Se ubicarían acá pensadores como San Agustín y F. Nietzsche, así como I. Kant, quien en su ensayo La Religión dentro de los límites de la Razón, se ocupa minuciosamente del mal en la naturaleza y del mal radical, para acercarse a su interpretación del pecado original.

No se puede hablar del hombre como malo por naturaleza como una cualidad atribuida a toda la humanidad. La naturaleza -según Kant- no puede recibir la calificación de buena o mala en sentido moral. Tal noción pertenece a un acto libre y responsable. Por "naturaleza del hombre" debe entenderse, por lo tanto, el principio subjetivo de la libertad. En este principio debe fundarse la posibilidad del mal y la inclinación del hombre hacia él. Hay en el hombre una disposición natural al bien en distintos niveles, mas existe también una propensión al mal. Esta inclinación no puede consistir en mera disposición física, que no puede imputarse al hombre, sino en el principio subjetivo libre "como fundamento de tener máximas contrarias a la ley moral". Como lo subraya Ricoeur en sí mismo como otro, es el amor de sí, la estima en sí, la base de esa inclinación al mal (Ricoeur, 1990:228).

La propensión al mal, como principio formal de todo acto malo, no puede venir de la sensibilidad y de sus inclinaciones, ya que no pertenece al orden moral, tampoco de una perversión de la razón: "el hombre no es ni bestia ni demonio". El hombre no puede menos que percibir la fuerza de la obligación de la ley moral, se siente, por otra parte, afectado por los motivos sensibles a consecuencia de su disposición natural, que en sí misma es inocente. Dicha propensión es, según Kant, una tendencia natural al mal y puesto que esta tendencia es culpable, se le puede llamar un mal radical e innato a la naturaleza humana, del que, sin embargo, el hombre es la causa.

Respecto al tema del origen del mal, no se puede hablar de un origen temporal reportado a una causa anterior determinante, puesto que su principio es siempre interior, radicado en el mal uso de la libertad. De manera que solo puede hablarse de un origen racional. En esta perspectiva, la peor explicación del origen del mal es 
representarlo como una herencia que nos viene de nuestros primeros padres, en clara alusión a la idea del pecado original.

Las tesis de Kant se inscriben en la visión ética del mal, que es entendida por Ricoeur como una interpretación según la cual se retoma el mal en la libertad en la mayor medida posible (Ricoeur, 2004:15). Es una ética de la obligación. La visión ética del mal conduce a una visión ética del mundo. Para ésta, el mal es un invento de la libertad. Para esta visión, la libertad se revela en su aspecto más profundo como un poder hacer y un poder ser. La libertad que supone el mal es una libertad capaz de separarse, desviarse, subvertirse, deambular. Esta "explicación" mutua del mal por la libertad y de la libertad por el mal es la esencia de la visión ética del mundo y del mal. Para Ricoeur esta visión ética del mundo ha estado vinculada a una interpretación de símbolos clave en la cultura occidental (Triana, 2002). La explicación del mal por la libertad supone eventos previos: la culpabilidad y la concomitante confesión del mal en cuanto mal cometido. Estos acontecimientos son relevantes porque con ellos nace la conciencia, que conduce al sujeto al descubrimiento de la libertad.
El filósofo francés reconoce que los descubrimientos implicados en la atribución del mal a la libertad misma constituyen en buena medida el descubrimiento del sujeto mismo y de sus posibilidades, sin embargo, esta visión tiene sus limitaciones, se trata de una "puerta estrecha", pues se corre el riesgo de elegir una perspectiva unidimensional, que no permitiría el acceso a otras fuentes del mal que afligen igualmente al individuo. Esto hace referencia a la visión trágica de la vida, que supone que el mal es anterior a la especie humana, es algo que ya está allí y que nos resulta interesante por el nivel de su exterioridad.

\section{El mal en Ricoeur}

A la visión ética del mundo se opone la visión trágica del mundo representada por autores como Plotino, Spinoza y Hegel. Aunque también aquí se expresan excesos, que incluso tienden a la disolución del mal.

Las dos vías por lo tanto evidencian fracaso, por lo que se impone la necesidad de volver a un esfuerzo interpretativo más fiel y riguroso de los símbolos esenciales en los que se ha expresado la experiencia de la vida humana. Ricoeur analiza e interpreta el lenguaje del mal expresado a través de símbolos. 
Si podemos enunciar un elemento que condensa el pensamiento de Ricoeur es “el símbolo da qué pensar" y esto significa que hay tres etapas en su comprensión: fenomenológica, hermenéutica y filosófica. El símbolo es una figura susceptible de elaboración lingüística (Tyman 2000:459). La labor de la filosofía es pensar a partir de lo que el símbolo entrega. Ricoeur apela a la literatura penitencial para revelar los símbolos del mal. Esta literatura se refiere a aquellos textos a partir de los cuales se estableció y fijó el significado de la culpabilidad.

Analizando los símbolos primarios del mal, Ricoeur sostiene que el ser humano ha pasado por tres grandes niveles de conciencia del mal, a saber: impureza, pecado $\mathrm{y}$ culpabilidad, expresados en los símbolos de la mancha, del cautiverio, y del peso, respectivamente. Los símbolos primarios constituyen abstracciones a partir de los símbolos secundarios, que son los mitos del principio y fin del mal. En efecto, el mito le otorga a la humanidad una universalidad concreta. Esto quiere decir que la humanidad entera es simbolizada en un hombre ejemplar, como es el caso de Adán.

La experiencia del mal se expresa en un lenguaje simbólico porque esa experiencia contiene elementos contradictorios a nivel conceptual. Toda la gama de símbolos primarios del mal (mancha, pecado, culpa) se orienta a lo que él denomina (con ayuda de Lutero) "siervo albedrío", concepto que contrapone al de "libre albedrío" y que expresa en un solo concepto libertad y servidumbre en el hombre. En un vasto análisis de diversos mitos, Ricoeur muestra el extenso proceso, desde la concepción del mal como algo exterior al hombre (la mancha) hasta su plena interiorización (la culpa). El mal es mucho más que un no-ser. Es un algo que entra al mundo, es exterior al ser humano. Es precisamente éste, el nivel que queremos analizar.

¿Cómo se hace posible el mal? El mal es posible debido a la falibilidad humana (Ricoeur 2004:21). El mal entra al mundo por el hombre. Esa falibilidad humana no se debe a que sea apenas intermediario entre el ángel y la bestia, sino porque el hombre es intermediario en sí mismo, de sí a sí mismo. Su característica ontológica de ser intermediario estriba precisamente en que su acto de existir es el acto mismo de operar mediaciones entre todas las modalidades de la realidad. El ser humano es capaz de todas las virtudes y de todos los vicios. 
Aun así, Ricoeur ha abierto muchas puertas en su análisis de la exterioridad del mal que al final no se han cerrado por completo. Algunos ejemplos: ¿Cuál es entonces el rol del Adversario si el mal es exterior al hombre? ¿Se trata de un simple instigador-facilitador o es mucho más que eso? Sí el mal es algo que de alguna manera ha entrado ¿de dónde ha venido?

\section{El origen del mal}

Plantear el tema del origen del mal implica en Ricoeur, remitirse primero al concepto de origen. El origen es importante pues no tendría sentido alguno hablar de una experiencia presente de proyección de los orígenes, individual o colectiva, psicológica, histórica y antropológicamente. Pues el origen ha sido siempre contado ya, de ahí que podamos, tras el hecho, formar el plan de volver hacia él. Ineludiblemente, referirse al origen supone recurrir al uso de representaciones antropomórficas (engendrar, luchar, mandar). En ese sentido, podríamos decir que, desde el punto de vista religioso el origen mismo habla haciendo que se hable de él.

En la Simbólica del mal, Ricoeur reconoce tanto la universalidad del mal como las diferentes formas en que culturas particulares han intentado hacer frente a esa realidad. No todas van a hablar de la misma manera de "pecado" o culpa", pero todas las culturas tendrán sus propios "símbolos primarios" para explicar la experiencia de la "falla". En la terminología de Ricoeur, los símbolos primarios son colocados juntos en mitos que luego dan origen a especulaciones filosóficas y explicaciones lógicas. Para Ricoeur un mito no es una falsa explicación por medio de imágenes y de fábulas, sino un relato tradicional referido a acontecimientos ocurridos en el origen de los tiempos y destinado a fundar la acción ritual de los hombres de hoy y, de modo general, a instaurar todas las formas de acción y de pensamiento mediante las cuales el hombre se comprende a sí mismo dentro de su mundo (Ricoeur, 2004:171).

Ricoeur describe cuatro mitos o tipos míticos de representación concernientes al origen y el fin del mal, cuatro formas en las que las sociedades humanas han entendido el problema del mal:

1. El drama de la creación y la visión ritual del mundo: Esta es una visión dualística del conflicto entre el bien y el mal, son ambos primitivos. La creación es el trabajo de un Dios bueno luchando contra 
un caos maligno. Los mitos teogónicos y cosmogónicos de las culturas mesopotámicas son las antiguas ilustraciones de esta perspectiva.

2. El Dios malvado y la visión trágica de la existencia: Este es el mundo de la tragedia griega. Aquí la falla aparece indistinguible de la misma existencia del héroe trágico.

3. El mito del alma exiliada y la salvación a través del conocimiento: Es también un mito dualístico, pero de un dualismo antropológico en el que se divide al humano en cuerpo y alma. El mal es inherente a la naturaleza humana. La salvación viene con el conocimiento o gnosis.

4. El mito adámico: es el mito antropológico clásico.

Dentro de esos cuatro mitos, el último tiene preeminencia en nuestra cultura occidental por la doctrina del pecado original y la fuerza de la cristología como salvación del hombre, pero no significa que los otros mitos se han abolido, sino que son incorporados a partir del mito adámico.

Esta investigación se centrará en el mito adámico, que es el más extremo al desdoblar el origen del mal y del bien. El mito muestra la consistencia de un origen radical del mal distinto del origen más originario del ser-bueno de las cosas. Ricoeur advierte cómo en el mito Adámico no se logra concentrar, ni reabsorber el origen del mal en la sola figura de un hombre primordial, se incluye asimismo al Adversario, a la serpiente que se convertirá en el diablo. Así, el mito Adámico suscita varias figuras contrapuestas a la figura central del Hombre y que constituye el núcleo de la externalidad.

Aquí es el hombre quien introduce el mal como consecuencia de una libre decisión. Adán desobedece a Dios, come el fruto del Árbol de la Ciencia del Bien y del Mal y, a partir de ese instante simbólico, desaparece la inocencia, se desencadena el sufrimiento y la muerte se constituye en meta insoslayable de la vida.

El mito adámico tiene tres características: 1) el mito etiológico relaciona el origen del mal a un ancestro de la raza humana y cuyas condiciones son homogéneas a las nuestras. 2) Su intención es establecer un origen radical del mal diferente del origen primordial $y$ bueno de las cosas. 3) Hay otros agentes en la historia (serpiente, otros humanos, árboles). La intención central del mito es ordenar las otras figuras en relación con la figura de Adán y entenderlas 
en conjunción con él como figuras periféricas en la historia en la cual ese primer hombre es el principal protagonista. En su forma más pura el mito exonera -perennemente- a Dios de toda complicidad en el mal.

\section{EL mito adámico: Génesis 2-3}

Antes de analizar los capítulos 2 y 3, Ricoeur aclara que el capítulo precedente (1) no es un relato, sino un poema didáctico. A partir de Génesis 2 se verifica la creación del hombre, de los animales y de la mujer... y también la irrupción del mal" (Ricoeur, 2004: 54). Según Ricoeur, si algo significa la creación es por lo menos el sentido negativo, que la criatura no es Creador. Al exteriorizarse a sí mismo, Dios establece en la exterioridad una naturaleza que de ahora en adelante, existe, sino por sí misma, sí por lo menos en sí misma. (Ricoeur, 2004:59). Dios se distancia de aquellos a los que él ha alejado de sí. Creación es separación. Cielos y tierra comienzan a existir "en sí", sin ser no obstante "para sí".

La primera mención que se hace del problema del mal en el Génesis es en 2:9 "Y Jehová Dios hizo nacer de la tierra todo árbol delicioso a la vista, y bueno para comer; también el árbol de vida en medio del huerto, y el árbol de la ciencia del bien y del mal." La desobediencia de la primer pareja humana ocasiona la "entrada" del pecado en el mundo. En 2:8-17 se relata cómo Dios ha plantado un jardín en el Edén. Dos árboles reciben especial atención: Uno es el Árbol de la Vida, que después de la desobediencia de Adán y Eva, Dios lo considera de riesgo continuo para el hombre y lo hace inaccesible (3:22-24). El otro es el Árbol del Conocimiento del Bien $y$ del Mal, en otras palabras, del discernimiento total, que marca la limitación de la libertad del hombre y su relación responsable para con Dios.

\section{La serpiente}

Un elemento vital en la comprensión del problema del mal en el Génesis, es el papel de la Serpiente, que aparece al inicio del cap. 3 y es descrita como el más astuto de todos los animales.1 La Serpiente

1. En efecto, el Antiguo Testamento reconoce la sutileza de la serpiente así como su ferocidad, aunque también se les declara animales inmundos en la ley mosaica (Lev. 11:10, 41,42). Desde la caída del hombre se le ha considerado como emblema de la vileza y la corrupción del pecado y de la condenación divina que sobre él pesa. Es interesante tomar en cuenta que la serpiente era también un animal muy significativo para otras culturas. Los egipcios se servían de la serpiente casi en todos sus símbolos, especialmente rela- 
aparece claramente en Génesis 2-3 como instrumento "externo" de tentación, ofreciendo a la mujer un destino mejor que el que Dios había establecido para la pareja. Así, la Serpiente apela a la satisfacción de las necesidades más básicas del ser humano: sustento, desarrollo ilimitado de las capacidades y deseo de controlar el destino de sus vidas sin depender de un ser superior (Carro, 1994:96).

Es preciso advertir que la identificación de la Serpiente del Génesis con Satanás es posterior al Antiguo Testamento. Si tenemos en cuenta que el documento Yahvista fue redactado más o menos durante el reinado de Salomón (Siglo X a.C.), la identificación plena de la Serpiente con Satanás se verifica hasta el Apocalipsis 12:9: "Y fue lanzado fuera el gran dragón, la serpiente antigua, que se llama diablo y Satanás, el cual engaña al mundo entero; fue arrojado a la tierra, y sus ángeles fueron arrojados con él". En el marco de esta asociación Serpiente-Satanás, si Dios es el creador de todo cuanto existe o ha existido, está claro que existe una potencia del mal anterior al

cionada con Osiris y Serapis. La serpiente en general designaba a la tierra y el agua. No era menos venerada la serpientes para griegos y romanos, quienes atribuían a la serpiente una virtud profética. J.F.M.

Noël. Diccionario de Mitología Universal. Tomo II. Edicomunicación S.A. Barcelona, 1991, p. 1174. hombre. Éste es independiente y posterior a la existencia de ese mal. Pareciera que Satanás ciertamente se identifica con la Serpiente, que existe una "personificación" del mal en Satanás, aunque este es un campo abierto a la polémica. Al respecto, Rudiger Safranski señala:

la historia del pecado original no deja entrever nada relativo a un poder del mal independiente del hombre, a un poder que pudiera servirle de excusa, justificándose como si fuera una víctima del mismo. El pecado original, a pesar de la serpiente, es una historia que se desarrolla únicamente entre Dios y la libertad del hombre. Tan sólo más tarde se hace de la serpiente un poder autónomo, una figura divina y antidivina (...) La personificación del mal, hasta llegar a convertirse en un poder autónomo más allá del hombre y de Dios, se consuma en el siglo XIII aproximadamente. En esa época están unificados ya todos los rasgos importantes en la imagen del diablo (Castillo Ávila, 2004).

Esta es una entre tantas posiciones, sin embargo, identifiquemos a la Serpiente con Satanás o no, lo cierto es que ésta representa un 
poder que está allí, que irrumpe sembrando la discordia entre Dios y la pareja primigenia.

La posición de Ricoeur respecto a Satanás o el Adversario -tal y como lo llama en el prólogo de Finitud y Culpabilidad- es al principio algo ambigua y enigmática. Simbólicamente es claro que está constantemente delatando, acusando y tentando al hombre a desviarse de la Ley de Dios. Por ello, Ricoeur señala:

Este infierno de la culpabilidad, engendro de la ley y de su maldición, encuentra su símbolo supremo en la misma figura de Satanás: es cosa sabida que al Diablo se le consideró no solamente el tentador por antonomasia, sino como el delator $y$ acusador del hombre en el gran proceso del juicio cósmico -así como a Cristo, por el contrario, se le consideraba como Abogado, como Paráclito. Por consiguiente no solo se alza el demonio por detrás de la transgresión, sino por detrás de la misma ley, en cuanto es una ley de muerte.

Ciertamente es el hombre el que toma la decisión de desafiar la orden del Creador y en adelante el mal será presentado como una relación rota, pero no se puede obviar la "contribución" que tiene la Serpiente como un elemento de esa exterioridad del mal. Como lo reconoce el teólogo luterano Frederick J. Gaiser, reconocer la falta humana no desmerece el rol o responsabilidad de otros actores (Gaiser, 1996:395). Hay pues un mal que antecede al hombre y que ya está allí y representada con el símbolo de la Serpiente:

En el seno mismo del mito adámico, la serpiente representa la otra cara del mal que trataban de relatar los demás mitos: el mal que ya está ahí, el mal anterior, el mal que atrae $y$ seduce al hombre. La serpiente significa que el hombre no inicia el mal. Lo encuentra. Para él, iniciar es continuar. Así, independientemente de la proyección de nuestra propia codicia, la serpiente representa la tradición de un mal más antiguo que ella misma. La serpiente es el Otro del mal humano.

La serpiente no debe ser considerada únicamente desde la perspectiva de su rol narrativo. Efectivamente representa la inescrutable dramatización de un mal que está ya ahí. Se ha puntualizado que la Serpiente no inicia el mal. ¿Pero quién o qué es la Serpiente? Ricoeur observa acer- 
tadamente que en el pensamiento hebreo se ha dado una desmitoligización completa de los demonios. No será sino hasta el Libro de Job, donde se mencionará expresamente a Satanás, no como ángel caído, sino como (todavía) miembro de la Corte Celestial. Resulta entonces significativo -dice Ricoeur- que el Yahvista, deliberadamente pasa de largo frente a la Serpiente en su proceso de desmitoligización, es decir, la mantiene allí, el mal no se reduce en su origen a Adán, sino que se ha introducido una figura exterior.

Aquí Ricoeur enfrenta lo que constituye nuestra principal inquietud: el origen real de la exterioridad del mal. Para el filósofo francés cabría dar una respuesta parcial; el Yahvista habría dramatizado, con la figura de la serpiente, un aspecto relevante de la experiencia de la tentación: la experiencia de cuasi-exterioridad:

la tentación sería una especie de tentación desde fuera; se convertiría en complacencia para la aparición que sitia al "corazón"; por último pecar sería una parte de nosotros mismos que no reconocemos. (Ricoeur, 2004:399).

Aunque reconoce que es un tema muy enigmático, Ricoeur ensaya dos explicaciones. En la prime- ra explicación concibe que en el drama de la creación, el origen del mal es coextensivo con el origen de las cosas. La Serpiente sería una parte de nosotros mismos. (Ricoeur, 2004: 399). Esta respuesta no resulta tan descabellada para Ricoeur en el tanto ya está presente en la Epístola de Santiago I, 13: "Cuando alguno es tentado, no diga que es tentado de parte de Dios; porque Dios no puede ser tentado por el mal, ni él tienta a nadie"; también en Pablo encontramos "evidencia" de esa seducción por nosotros mismos: "No os ha sobrevenido ninguna tentación que no sea humana; pero fiel es Dios, que no os dejará ser tentados más de lo que podéis resistir, sino que dará también juntamente con la tentación la salida, para que podáis soportar" (I Cor. 10, 13).

La serpiente es pues, representación de ese aspecto pasivo de la tentación, que flota en la frontera entre el adentro y el afuera. Se trata más bien de un "seudo-afuera" que solo se convierte en una realidad ajena gracias a la mala fe. Al argumentar a partir de esa seducción de la libertad por parte de la codicia, el individuo busca disculparse y declararse inocente a sí mismo acusando a "otro". Dice Ricoeur: 
Así, alegamos lo irresistible que son nuestras pasiones para justificarnos nosotros mismos; eso es, por lo demás, lo que hace a la mujer a la que Dios interroga tras el fatídico acto: ¿Porqué hiciste eso? Ella responde: "la serpiente me sedujo"; la mala fe se apodera, pues, de la cuasiexterioridad del deseo para disfrazarla de coartada de la libertad. (Ricoeur, 2004:399).

¿Se resuelve el enigma de la exterioridad del mal como una proyección psicológica de la codicia?2 Sería entonces la proyección de nuestro propio deseo en el objeto deseable, pero Ricoeur se cuida de no agotar el simbolismo de la Serpiente como proyección de la seducción del hombre por sí mismo.

Si en ese nivel estamos hablando de una cuasi-externalidad, podríamos hablar de "externalidad a secas" si se analiza el simbolismo de la Serpiente en el marco de la

2. En varios de los grandes ensayos antropológicos de Sigmund Freud se pretende demostrar que Adán, en la tradición rabínica, simboliza al Padre, y no al hijo, cuyo papel es ocupado por la serpiente que desea a Eva. Según los rabinos, la serpiente fue empujada por el deseo de suplantar a Adán de reinar en el mundo en su lugar y de poseer a Eva [...]. La serpiente está sobre todo acuciada por el deseo de reemplazar al padre primitivo. ya reseñada desmitologización, a la cual sobrevive la Serpiente en la teogonía y que representa esa cara del mal que no puede retomarse en la libertad responsable del hombre. Efectivamente hay aquí una especie de "grieta" en el intransigente monoteísmo judío que da paso a una interpretación de la Serpiente desde una incipiente demonología. ¿Podría esto dar origen a un limitado dualismo? Podría ser, en el tanto, en la propia Biblia es posible hallar referencias a mitos babilónicos como el de Enuma Elish en el cual Marduk crea el mundo de las piezas del derrotado Tiamat.3 Ciertamente un dualismo limitado y tímido parece emerger frente al categórico "Yo soy Jehová, y ninguno más hay; no hay Dios fuera de mí. Yo te ceñiré, aunque tú no me conociste", de Isaías 45:6. La opacidad del símbolo se presenta de nuevo. Este dualismo limitado se presenta no solo por la experiencia humana de las fuerzas del mal y por la dificultad de adscribir toda catástrofe a Yahvé, mientras que al mismo tiempo se pretende mantener "que Dios es bueno".

3. "Despiértate, despiértate, vístete de poder, oh brazo de Jehová; despiértate como en el tiempo antiguo, en los siglos pasados. ¿No eres tú el que cortó a Rahab, y el que hirió al dragón? ¿No eres tú el que secó el mar, las aguas del gran abismo; el que transformó en camino las profundidades del mar para que pasaran los redimidos?". Isaías 51: 9-10. 
La Serpiente forma parte ciertamente de la creación, pero como símbolo permitió concentrar el movimiento de concentración del mal en el hombre con un segundo movimiento que hace recaer el origen de éste en una realidad demoniaca pre- humana. Eventualmente

Un Malvado aparece primero como "abogado del diablo" en el consejo divino de Dios (Job 1-2), pero después asumido las dimensiones de una estrella caída.4 La indepen-

4. “Cómo caíste del cielo, oh Lucero, hijo de la mañana! Cortado fuiste por tierra, tú que debilitabas a las naciones. Tú que decías en tu corazón: Subiré al cielo; en lo alto, junto a las estrellas de Dios, levantaré mi trono, y en el monte del testimonio me sentaré, a los lados del norte; sobre las alturas de las nubes subiré, y seré semejante al Altísimo. Mas tú derribado eres hasta el Sol, a los lados del abismo. Se inclinarán hacia ti los que te vean, te contemplarán, diciendo: $¿$ Es éste aquel varón que hacía temblar la tierra, que trastornaba los reinos; que puso el mundo como un desierto, que asoló sus ciudades, que a sus presos nunca abrió la cárcel? Todos los reyes de las naciones, todos ellos yacen con honra cada uno en su morada; pero tú echado eres de tu sepulcro como vástago abominable, como vestido de muertos pasados a espada, que descendieron al fondo de la sepultura; como cuerpo muerto hollado. No serás contado con ellos en la sepultura; porque tú destruiste tu tierra, mataste a tu pueblo. No será nombrada para siempre la descendencia de los malignos".Isaías 14:12-20. dencia relativa de Satanás crece en el periodo entre testamentos y en el Nuevo Testamento.

A partir de esto cabría decir que el hombre no es el malvado absoluto, sino el malvado por seducción: pecar es ceder. Esta sería la segunda explicación.

\section{Conclusiones}

Estudiando los símbolos del mal, Ricoeur mantiene que el hombre ha concebido el mal desde la visión trágica a la visión ética del mal, o sea, ha recorrido el camino de la idea del mal como exterioridad, hacia la idea del mal como interioridad, expresada en primer lugar en los símbolos de la mancha, siguiendo por el pecado hasta llegar a la culpabilidad; y en segundo lugar, desde el mito trágico, pasando por el mito del drama de la creación y del alma exiliada, hasta el mito adámico, que es el mito ético por excelencia.

No obstante, como lo apunta Francisco Castillo Ávila, a pesar de este desarrollo de la autoconciencia humana sobre el mal, siempre hay un lugar para lo trágico expresado en el símbolo de la Serpiente que tienta a la pareja humana. Se verifica un movimiento desde lo trágico hacia lo ético, pero nunca se deja completamente de lado la 
concepción trágica, es decir, siempre está presente la concepción del mal como algo exterior al hombre y que en determinados momentos se vuelve a ella: es lo que se podría denominar: "el péndulo del mal: entre lo trágico y lo ético".

La lectura de los símbolos en el mito antropológico adámico, se orienta a la responsabilidad humana en el ingreso del mal al mundo, es decir, la falibilidad. Pero, la complejidad y el carácter enigmático de este documento Yahvista, y en general en el resto de las Escrituras a las que Ricoeur se refiere en Finitud y Culpabilidad y Pensar la Biblia, hace necesario también tener en cuenta el papel de figuras contrapuestas a la figura central del Hombre y que introducen el nivel de la externalidad en el origen del mal.

Esta externalidad puede ser una proyección psicológica de la codicia (cuasi-externalidad) o bien manifestarse por la inducción-seducción de la serpiente o Adversario, que podríamos llamar "externalidad a secas"; el caso es que hay una extermalidad allí que no se puede obviar. De ahí que sea necesaria una formulación más ecléctica: ciertamente nosotros damos inicio al mal, éste entra en el mundo por nosotros, pero sólo lo iniciamos a partir de un mal que ya está allí y del cual nuestro nacimiento es el símbolo impenetrable. En rigor, el hombre no es originador del mal, sino co-originador.

¿Cuál es entonces la conclusión para la ética? Si la ética es una de las mayores demandas del discurso cotidiano (Triana, 2002:99),

ésta tiene una respuesta limitada para comprender el mundo desde la perspectiva de una ética de la obligación. Esa ética de la obligación se enmarca en una visión del cosmos, según la cual se postula un orden eterno que lo constituye en un presente permanente.

Resulta interesante la conclusión a la que llega Castillo Ávila, quien cree que la postura trágica y la postura ética sobre el origen del mal no son necesariamente excluyentes. Pueden -dice- ser complementadas en una nueva concepción, que podría ser llamada "visión sintética y paradójica del mal"5. Desde nuestro punto de vista, esta sería una solución más o menos satisfactoria para un objeto de estudio que está indefectiblemente marcado por la opacidad.

5. Castillo Ávila, Francisco. Aportes de Paul Ricoeur a la comprensión del problema del mal. Facultad de Filosofía y Humanidades, Universidad de Chile, Santiago, marzo 2004:109 


\section{Bibliografia}

Begley, Sharon (2001), "The roots of evil". TIME, may 21.

Carro, Daniel et al. (editores) (1994), Comentario Bíblico Mundo Hispano. Tomo I Génesis. El Paso, Mundo Hispano.

Castillo Avila, Francisco (2004), Aportes de Paul Ricoeur a la comprensión del problema del mal. Santiago, Chile. Facultad de Filosofía y Humanidades.

Ferrater, José (2001), Diccionario de Filosofia, Tomo III. Madrid, Alianza Editorial.

Gaiser, Frederick J. (1999), "Paul Ricoeur's Myths of Evil in Biblical Perspective". World \& World, Volume XIX, Number 4, Fall.

Kant, Immanuel (2000), La Religión dentro de los límites de la Razón. Madrid, Editorial Alianza.

Kelly, Joseph F. (2001), The problem of evil in the Western Tradition: from the book of Job to the Modern Genetics. Collegeville, The Liturgical Press, Collegeville.
Noël, J.F.M. (1991), Diccionario de Mitología Universal. Tomo II. Barcelona. Editorial Edicomunicación S.A.

Ricoeur, Paul (2004), Finitud y Culpabilidad. Madrid.

(2000), Pensar la Biblia: estudios exegéticos y hermenéuticos. Barcelona, Herder.

(1990), Sí mismo como otro. México, Siglo XXI.

Ruiz de la Peña, Juan. (1988), Teología de la creación. Santander, Sal Terrae.

Triana, Manuel (2002), "Visión ética y visión trágica". Rev. Filosofía Universidad de Costa Rica, XL (101), 99-11, Juliodiciembre.

Tyman, Stephen (2000), Ricoeur and the problem of evil. en The Philosophy of Paul Ricoeur.

Woodward, Kenneth L. (2005), "Overcoming sin". Newsweek may 21. 